\title{
Evaluating the diagnostic accuracy of point-of-care ultrasound for cholelithiasis and cholecystitis in a canadian emergency department
}

\author{
Sameer Sharif ${ }^{1,2} \cdot$ Dean Vlahaki $^{1} \cdot$ Steven Skitch $^{1,2} \cdot$ Jenifer Truong ${ }^{1} \cdot$ Shane Freeman $^{3} \cdot$ Daniel Sidalak $^{4,5}$. \\ Andrew Healey ${ }^{1,2}$
}

Received: 9 August 2020 / Accepted: 14 December 2020 / Published online: 14 January 2021

(C) The Author(s), under exclusive licence to Canadian Association of Emergency Physicians (CAEP)/ Association Canadienne de Médecine d'Urgence (ACMU) 2021

\begin{abstract}
Objectives Cholelithiasis and cholecystitis are common conditions that frequently require patients to come to the Emergency Department (ED) and undergo diagnostic imaging. The purpose of this study was to evaluate the test characteristics of emergency physician performed point-of-care ultrasound (POCUS) to diagnose cholelithiasis and cholecystitis in a Canadian ED. Methods A health records review was performed on all ED patients $>17$ years of age for whom POCUS was performed to diagnose cholelithiasis and cholecystitis in a Canadian academic ED over a 5-year period. The sensitivity, specificity, predictive values, and likelihood ratios were calculated. The gold standard used for diagnosis was pathology, laparoscopy, radiology-performed comprehensive ultrasonography, followed by computed tomography scans.

Results A total of 577 patients were included in the study. The sensitivity and specificity of POCUS to diagnose cholelithiasis was $95.2 \%$ (95\% CI 91.1-97.8\%) and 93.1\% (95\% CI 90.1-95.4\%). The positive and negative likelihood ratios for POCUS to diagnose cholelithiasis were found to be 14 and 0.05 ; the negative predictive value was $97.6 \%$ (95\% CI 95.5-98.7\%). The sensitivity and specificity of POCUS to diagnose cholecystitis was $67.1 \%$ (95\% CI 54.9-77.9\%) and 97.6\% (95\% CI 95.9-98.8\%). The positive and negative likelihood ratios for POCUS to diagnose cholecystitis were found to be 28 and 0.34 ; the negative predictive value was $95.6 \%$ (95\% CI 93.9-96.8\%).

Conclusion POCUS is reliable for the diagnosis of cholelithiasis and for ruling in cholecystitis. In cases where POCUS is negative or indeterminate for cholecystitis, further imaging should be obtained as clinical suspicion warrants.
\end{abstract}

Keywords Retrospective $\cdot$ Point-of-care ultrasound $\cdot$ Cholelithiasis $\cdot$ Cholecystitis

\section{Résumé}

Objectifs La cholélithiase et la cholécystite sont des troubles médicaux courants qui obligent fréquemment les patients à se rendre aux urgences et subir une imagerie diagnostique. Le but de cette étude était d'évaluer les caractéristiques des tests de l'échographie au point d'intervention (POCUS) effectuée par des médecins urgentistes pour diagnostiquer la cholélithiase et la cholécystite dans une urgence canadienne.

Supplementary Information The online version contains supplementary material available at https://doi.org/10.1007/s4367 8-020-00068-6.

Sameer Sharif

sameer.sharif@medportal.ca

1 Department of Medicine, Division of Emergency Medicine and Critical Care, McMaster University, 237 Barton St East, 2nd Floor McMaster Wing, Room 252, Hamilton General Hospital, Hamilton, ON L8L 2X2, Canada

2 Department of Medicine, Division of Critical Care, McMaster University, Hamilton, ON, Canada
3 Department of Medicine, Division of Emergency Medicine, Western University, London, ON, Canada

4 Department of Medicine, Division of General Internal Medicine, Sunnybrook Health Sciences Centre, Toronto, ON, Canada

5 Department of Hospitalist Medicine, St. Mary's General Hospital, Kitchener, ON, Canada 
Méthodes Un examen des dossiers médicaux a été effectué sur tous les patients des services d'urgence, âgés de plus de 17 ans pour lesquels POCUS a été réalisée pour diagnostiquer la cholélithiase et la cholécystite dans un service d'urgence universitaire canadien sur une période de 5 ans. La sensibilité, la spécificité, les valeurs prédictives et les rapports de vraisemblance ont été calculés. L'étalon-or utilisé pour le diagnostic était la pathologie, la laparoscopie, l'échographie complète réalisée par radiologie, suivie de la tomodensitométrie.

Résultats Au total, 577 patients ont été inclus dans l'étude. La sensibilité et la spécificité de POCUS pour diagnostiquer la cholélithiase étaient de 95.2\% (IC 95\% 91.1-97.8\%) et 93.1\% (IC 95\% 90.1-95.4\%). Les rapports de vraisemblance positifs et négatifs pour POCUS pour diagnostiquer la cholélithiase se sont révélés à 14 et 0.05 ; la valeur prédictive négative était de 97.6\% (IC à 95\% 95.5-98.7\%). La sensibilité et la spécificité de POCUS pour diagnostiquer la cholécystite étaient de 67,1\% (IC à 95\% 54.9-77.9\%) et de 97.6\% (IC à 95\% 95.9-98.8\%). Les rapports de vraisemblance positifs et négatifs pour POCUS pour diagnostiquer la cholécystite se sont révélés à 28 et 0.34 ; la valeur prédictive négative était de $95.6 \%$ (IC à 9.5\% 93.9-96.8\%).

Conclusion POCUS est fiable pour le diagnostic de la cholélithiase et de la cholécystite. Dans les cas où le POCUS est négatif ou indéterminé pour la cholécystite, une imagerie supplémentaire doit être obtenue en cas de suspicion clinique.

\section{Clinician's capsule}

\section{What is known about the topic?}

ED physicians require comprehensive ultrasound to diagnose cholelithiasis and cholecystitis; however, ultrasound access can be limited outside of daytime hours.

\section{What did this study ask?}

What are the test characteristics of emergency physician performed POCUS to diagnose cholelithiasis and cholecystitis in a canadian ED.

\section{What did this study find?}

POCUS has very high sensitivity and specificity to diagnose cholelithiasis. POCUS also has high specificity in diagnosing cholecystitis.

Why does this study matter to clinicians?

Appropriately trained and credentialed ED physicians should be encouraged that POCUS is a reliable tool to aid in the diagnosis of cholelithiasis and cholecystitis.

\section{Introduction}

\section{Background}

Cholecystectomy is the second most common operation performed in Canada [1]. Physical exam and laboratory tests are not sufficient to rule out cholecystitis [2]. Comprehensive ultrasound by radiology is the gold standard for the diagnosis of gallbladder pathology with a sensitivity and specificity of $94 \%$ and $78 \%$, respectively [3]. However, obtaining a comprehensive ultrasound in the Emergency Department (ED) can be challenging, as many EDs do not have access to ultrasound outside of daytime hours [4].
Point-of-care ultrasound (POCUS) can be used to assess for cholelithiasis and cholecystitis in the ED. When compared to POCUS, comprehensive ultrasound performed by radiology has been shown to result in a 120 min longer ED length of stay [5]. POCUS has the potential to aid in making these diagnoses sooner that may result in decreased patient morbidity, length of stay in the ED, need for additional imaging, and earlier consultation with General Surgeons for definitive management.

\section{Importance}

POCUS is an integral part of Emergency Medicine with the Canadian Association of Emergency Physicians (CAEP) issuing a position statement on its use [6]. Coincidentally, CAEP does not mention the use of POCUS for cholecystitis. Given that the only studies examining the test characteristics of POCUS for gallbladder pathology have been small single-center studies, it is important to assess those same characteristics at a different center with a larger population.

\section{Objectives}

The purpose of this study is to evaluate the test characteristics of emergency physician-performed POCUS to diagnose cholelithiasis and cholecystitis in a Canadian ED.

\section{Methods}

\section{Study design and setting}

This was a health records review of all POCUS studies for cholelithiasis and cholecystitis at an academic Canadian ED. All studies for cholelithiasis, cholecystitis, choledocholithiasis, and right upper quadrant pain were identified on Q-Path, (Telexy Healthcare, Maple Ridge, BC, Canada) the 
online database for POCUS scans from December 1, 2011 to December 4, 2015. All scans were performed by physicians with Registered Diagnostic Medical Sonographer credentials or resident physicians completing POCUS fellowship training (see Supplementary Appendix).

\section{Study population}

All patients $>17$ years of age who had an ultrasound to investigate right upper quadrant pain were included in the study.

\section{Data collection}

A previously published framework for completing medical record review studies was followed [7]. Every POCUS study underwent a quality assurance process by comparing the physician's initial impression with patient clinical outcomes and best available gold standard from a review of the chart. If pathological specimen was not available, the gold standard was considered to be laparoscopy, comprehensive ultrasound, and computed tomography (CT) scan, respectively. This data were compiled using Microsoft Excel for statistical analysis (Microsoft, Redmond, WA, USA). Trained abstractors were medical students who were blinded to the hypothesis.

For the purposes of this study, cholelithiasis was defined as the presence of a highly reflective echogenic focus within the gallbladder lumen with posterior acoustic shadowing. Cholecystitis was diagnosed if two of the following were present: sonographic Murphy's sign, anterior gallbladder wall thickening $>3 \mathrm{~mm}$, and pericholecystic fluid [8]. Choledocholithiasis was defined as the presence of gallstones within the bile duct. For the purposes of this study, all patients with choledocholithiasis were considered to have to cholelithiasis as well. Indeterminate scans were considered to be negative for both pathologies. Additionally, if patients visited an ED again for the same issue in the next 30 days, a thorough review was done to ensure whether the patient was diagnosed with cholelithiasis or cholecystitis.

\section{Outcome measures and analysis}

The diagnostic accuracy of POCUS for cholelithiasis and cholecystitis were the primary outcomes. The data gathered were used to calculate the specificity, sensitivity, predictive values, and likelihood ratios of POCUS to diagnose cholelithiasis and cholecystitis were calculated separately. The 95\% confidence intervals were also calculated using the Wilson score.

\section{Ethical issues}

This study was subject to ethics review and was approved by the Hamilton Integrated Research Ethics Board prior to data abstraction commencement.

\section{Results}

There were 966 patients that were identified by our search strategy. Three-hundred and twenty duplicate records were excluded, with another 69 further excluded because POCUS was performed to investigate something other than gallbladder pathology (Fig. 1). A total of 577 patients were used in the final analysis.

Two hundred and five patients had positive POCUS findings for cholelithiasis and 372 patients had negative findings (Fig. 1). There were 27 false positives and 9 false negatives for cholelithiasis (Fig. 1). Fifty-nine patients had positive

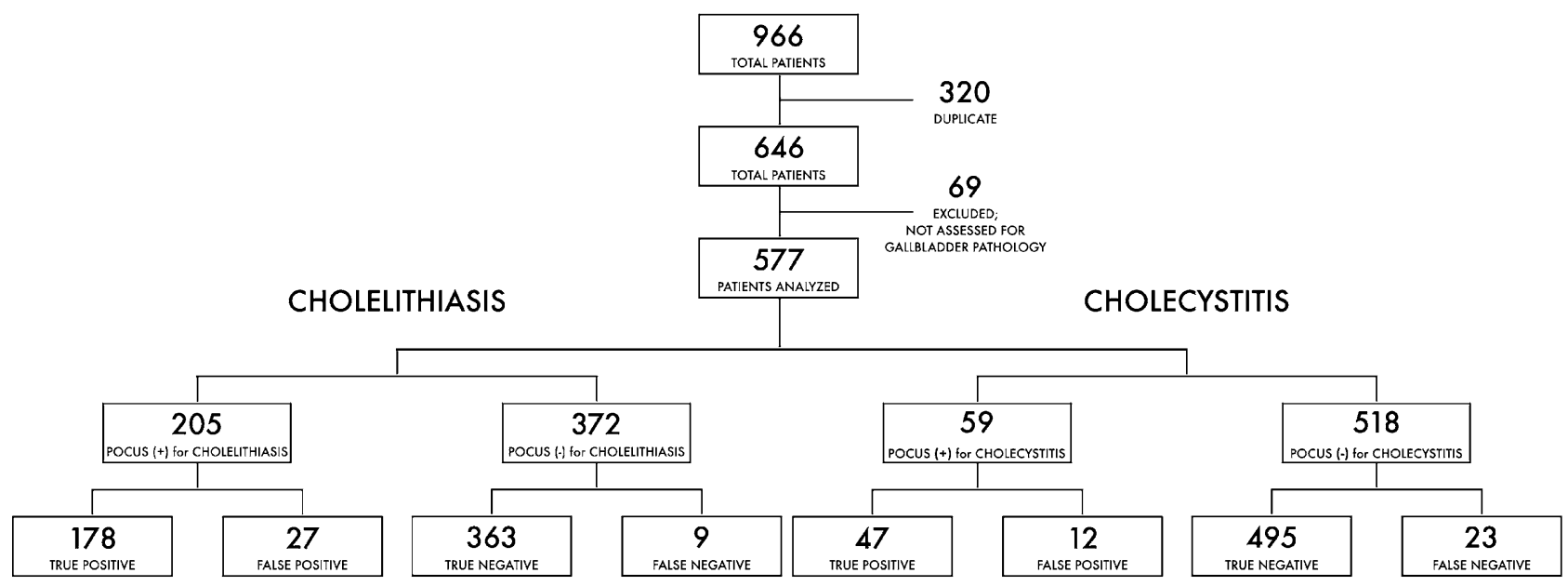

Fig. 1 Study flowchart for patient assessed for cholelithiasis and cholecystitis (POCUS point-of-care ultrasound) 
POCUS findings for cholecystitis and 518 patients had negative findings (Fig. 1). There were 12 false positives and 23 false negatives for cholecystitis (Fig. 1). In addition, Cohen's kappa statistic was determined to be 0.93 .

\section{Cholelithiasis}

The sensitivity and specificity for POCUS to diagnose cholelithiasis were found to be $95.2 \%$ (95\% CI 91.1-97.8\%) and $93.1 \%$ (95\% CI 90.1-95.4\%). The positive and negative likelihood ratios for POCUS to diagnose cholelithiasis were found to be 14 and 0.05 . Furthermore, the negative predictive value of POCUS for cholelithiasis was found to be $97.6 \%$ (95\% CI $95.5-98.7 \%$ ).

\section{Cholecystitis}

The sensitivity and specificity of POCUS to diagnose cholecystitis was 67.1\% (95\% CI 54.9-77.9\%) and 97.6\% (95\% CI 95.9-98.8\%). The positive and negative likelihood ratios for POCUS to diagnose cholecystitis were found to be 28 and 0.34 . The negative predictive value for POCUS to diagnose cholecystitis was found to be $95.6 \%$ (95\% CI 93.9-96.8\%).

\section{Discussion}

Our results are comparable to the test characteristics of comprehensive ultrasound (sensitivity: $84 \%$; specificity: $99 \%$ ) to detect cholelithiasis in the literature and support the use of POCUS for this diagnosis [3]. Although our specificity for detecting cholecystitis was higher in comparison to comprehensive ultrasound ( $97.6 \%$ vs $78 \%$ ), our sensitivity was considerably lower (67.1\% vs 94\%) [3]. This was expected as the true utility of ultrasound is in determining the presence or absence of cholelithiasis. The clinical examination and history in the presence of the diagnosis of cholelithiasis largely confirms or refutes the diagnosis of cholecystitis [2]. These results are comparable to the current literature on POCUS for cholecystitis [9].

Literature has shown that clinicians are clinically competent after performing 25 ultrasounds of the gallbladder [10]. With many EDs not having POCUS readily available, the Emergency Medicine community needs to continue to address the barriers to its use for the diagnosis of common medical conditions [4].

Strengths of our study include its large sample size, adherence to a strict protocol, and a robust review of the medical records with trained abstractors using specific data abstraction forms. In addition, interobserver reliability was high in the data abstraction process. Additionally, all scans were subject to a rigorous quality-assurance process.

\section{Limitations}

In addition to the retrospective nature of this study performed at a single center, another limitation is the lack of consecutive patient enrolment as not all patients suspected of cholelithiasis and cholecystitis had an ultrasound performed by Emergency Physicians. This limited our data set and could have potentially overestimated our results through selection bias. Finally, the individuals who were performing the POCUS in this study were expert emergency physicians with additional training; as such these results may not generalizable to many EDs.

\section{Conclusion}

POCUS by appropriately trained and credentialed ED physicians is reliable for the diagnosis of cholelithiasis and for ruling in cholecystitis. In cases where POCUS is negative or indeterminate for cholecystitis, further imaging should be obtained as clinical suspicion warrants. CAEP and other Emergency Medicine organizations should be encouraged to incorporate POCUS for cholelithiasis and cholecystitis as a skillset to develop for all emergency physicians.

Funding None.

\section{Compliance with ethical standards}

Competing interests None declared.

\section{References}

1. Shaffer EA, Thomson ABR, Canadian Association of G, Canadian Association for the Study of the L. First principles of gastroenterology: the basis of disease and an approach to management. Toronto: Medicine Group; 2005.

2. Trowbridge RL, Rutkowski NK, Shojania KG. Does this patient have acute cholecystitis? JAMA. 2003;289(1):80-6.

3. Shea JA, Berlin JA, Escarce JJ, Clarke JR, Kinosian BP, Cabana $\mathrm{MD}$, et al. Revised estimates of diagnostic test sensitivity and specificity in suspected biliary tract disease. Arch Intern Med. 1994;154(22):2573-81.

4. Stein JC, Jacoby VL, Vittinghoff E, Wang R, Kwan E, Reynolds T, et al. Differential use of diagnostic ultrasound in U. S. Emergency departments by time of day. West J Emerg Med. 2011;12(1):90-5.

5. Wilson SP, Connolly K, Lahham S, Subeh M, Fischetti C, Chiem A, et al. Point-of-care ultrasound versus radiology department pelvic ultrasound on emergency department length of stay. World J Emerg Med. 2016;7(3):178-82.

6. Lewis D, Rang L, Kim D, Robichaud L, Kwan C, Pham C, et al. Recommendations for the use of point-of-care ultrasound (POCUS) by emergency physicians in Canada. CJEM. 2019;21(6):721-6. 
7. Worster A, Haines T. Advanced statistics: understanding medical record review (MRR) studies. Acad Emerg Med. 2004;11(2):187-92.

8. Alobaidi M, Gupta R, Jafri SZ, Fink-Bennet DM. Current trends in imaging evaluation of acute cholecystitis. Emerg Radiol. 2004;10(5):256-8.
9. Ross M, Brown M, McLaughlin K, Atkinson P, Thompson J, Powelson S, et al. Emergency physician-performed ultrasound to diagnose cholelithiasis: a systematic review. Acad Emerg Med. 2011;18(3):227-35.

10. Gaspari RJ, Dickman E, Blehar D. Learning curve of bedside ultrasound of the gallbladder. J Emerg Med. 2009;37(1):51-6. 